\title{
Book review: Savannas of Our Birth: People, Wildlife, and Change in East Africa
}

\author{
Eric J Lovell ${ }^{1 *}$ and Mara J Goldman ${ }^{1,2}$
}

\author{
Book details \\ Reid, RS \\ Savannas of Our Birth: People, Wildlife, and Change in East Africa. \\ Berkeley, CA: University of California Press; 2012. \\ Hardcover, 416 pages; ISBN: 9780520273559
}

Keywords: Savanna ecology; Human-environment interaction; Environmental change

The influence of human activity on ecological systems has long been a polarizing topic within the scientific community and beyond. Savanna ecosystems in particular highlight much that is at stake in such debates: often romanticized pristine untouched nature on the one hand or as the site of human beginnings on the other. Varying interpretations often diverge regarding the influence and importance of humans in African savanna systems. This most often occurs along disciplinary lines, with ecologists focusing on ecological processes while either ignoring the role of humans or demonizing their behaviors, pastoralists in particular. Social scientists, in contrast, often focus on the ways pastoralists work and survive in such areas, with only cursory treatment of the complex ecologies they continue to co-create. It is therefore refreshing - perhaps even inspiring - to find an analysis of East African savannas where various camps of thought are placed in conversation and a broad spectrum of positions are embraced as Robin Reid so eloquently does in Savannas of Our Birth: People, Wildlife and Change in East Africa. In this path-breaking book, Reid pursues a middle ground that blends dialogues from conservation science, pedology, and disturbance ecology with human ecology, anthropology, and human geography. Reid also blurs the boundaries between popular and scientific literature and knowledge by writing in an accessible manner (endnotes are used to keep references from

\footnotetext{
* Correspondence: eric.lovell@colorado.edu

'Department of Geography, University of Colorado, Boulder, CO, USA Full list of author information is available at the end of the article
}

cluttering the text) and by weaving the words of pastoralists into the text itself.

The book addresses the over-arching question of how humans can be seen as part of the savanna ecosystem. In doing so, Reid refers to global discourses on pastoralism, wildlife conservation, desertification, wildlife poaching, climate change, human-wildlife conflict, and population growth, amongst other topics. Reid combines her own empirical work as an ecologist in Kenya and Tanzania with the work of other scholars, as well as the views of pastoralists with whom she has worked. Savannas of Our Birth is a powerful book for teaching and research on humanenvironment interactions and conservation, while also contributing to policymaking as well as conservation and development practice. It is well suited for teaching in both undergraduate and graduate classes and the chapters can be used independently. We used Chapter 2 in an upperlevel undergraduate course on Africa with great success.

Inevitably, taking on a project with such a large scope means that not all areas of inquiry will be covered in necessary depth. We suggest that an important area that could have received more attention in the book includes a comprehensive analysis on the global political economic aspects of savanna ecosystems. Our review and critique comes from the perspective of nature-society geographers with a political ecology focus. This means that we are both delighted to see such an interdisciplinary endeavor and yet yearning for more recognition of politics and power.

Chapter 1 is perhaps Reid's most notable contribution to studies of human-environment interactions. In this 
chapter, Reid introduces the project's core concept of understanding savannas from the middle ground, which unfolds in greater detail throughout the remaining 11 chapters. The middle ground is presented as an intermediary perspective that rests between those who value pastoral livelihood practices (human-centric) and those who value the protection of wildlife (eco-centric), the latter of which coincides with the Western philosophical notions that humans should be separate from nature. The middle ground perspective is, in many ways, an attempt to demystify the distinction between nature and culture by reimagining a savanna where human activities play a fundamental role in the construction of the savanna ecosystems that we understand today. This position moves scientific interpretations of savanna ecology away from early equilibrium-based thinking that has predominately shaped enduring global discourses, such as desertification, (neo)Malthusianism, and Hardin's tragedy of the commons, to instead engage with place-based and empirically driven connections among international social, political, and economic processes and landscape change.

Reid uses the subsequent chapters to present African savannas as multifaceted and complex ecosystems, driven by variegated rainfall regimes and/or disturbances (i.e. infectious diseases, fires). She provides an in-depth analysis of the physical geography and biophysical processes that constitute African savannas and situates them as part of the essential building blocks of the creation of life. By starting at the Pre-Cambrian period and moving into what is now considered the Anthropocene, a period dominated by humans as 'ecosystem engineers', Reid balances the role of nonhumans and humans in the engineering of African savannas. The East African savanna and the Great Rift Valley, in particular, are noted as the site of the oldest footprints of humankind, a relic of society's foundation. Reid uses this long telescope on our history to connect the reader to the African savanna as the nucleus of human society.

In Chapters 3 to 5, Reid provides a detailed analysis of the livelihood practices common in savanna ecosystems. In some instances, Reid steps out of Africa entirely to demonstrate the similarities between African nomadic systems and nomadic movements found in central Asia during large-scale climatic perturbations. While much anthropological work has focused on nomadism and strategies of mobility, Reid's constant engagement with the cultural and political ecological contexts more closely matches the work of Galaty and Johnson (1990) and Turner (2004), respectively.

Central to the analysis in these chapters is the close relationships among livestock herders, livestock, and migratory wildlife, particularly grazing and ungulate populations. Reid's long-term experience and commitment to socially engaged ecological research in the Kenyan and
Tanzanian rangelands come through in these sections as her own methodologies and research projects have led to fascinating discoveries of human-wildlife dynamics. For instance, by conducting nighttime population counts, Reid and colleagues have revealed astonishing patterns of coexistence between wildlife grazing and human settlement. While this analysis provokes greater research into the spatially and temporally dynamic ecologies of humanwildlife interactions, it demonstrates that the existence of wildlife cannot be separated from land tenure regimes, land-use management, and culture.

Reid uses Chapters 6 and 7 to expand her analysis of human-wildlife interactions, by asking when, why, and how pastoralists, livestock, and wildlife co-exist. Reid advances her argument towards a middle ground by presenting positive and negative perspectives of grazing pressures on the foundation of savanna ecologies. Indigenous management regimes are presented that have been used by herders to sustain grazing pressures on the rangelands and maintain a compatible relationship with grazing wildlife. She also suggests that this balance has been challenged by shifting livelihood practices, from herding towards crop cultivation. The diversification of livelihood practices has altered the how, when, and where humans, livestock, and wildlife can co-exist.

The most encapsulating process that has shifted humanwildlife relations across African rangelands has been the emergence of management strategies that align with Western ideals of protecting 'nature'. In the four chapters (Chapters 8 to 11) that lead up to the concluding chapter, Reid examines specific case studies of parks and protected areas that occupy approximately $10 \%$ of the East African savanna and that happen to be where humans, livestock, and wildlife congregate. Her analysis illustrates how landscapes that have been set aside under the veil of biological preservation and the protection of 'natural' ecological systems have been driven by Western ideals of nature. Reid uses the iconic landscapes of Kenya and Tanzania (Serengeti-Mara, Amboseli, and Ngorongoro) to demonstrate how the engineering of these landscapes for conservation has actually failed to capture 'wild Africa' through the very act of excluding the essential 'ecosystem engineer', humankind. She thus adds to a growing literature that challenges the Western conservation model by illustrating how pastoralism is essential to a healthy savanna ecosystem.

For Reid, the middle ground perspective - of maintaining savannas for people and wildlife - can be accomplished through moderation, a skill that Reid so strongly conveys in her book. Moderation means moving away from blaming pastoralists for environmental degradation towards understanding the ways that pastoral practices may in fact facilitate a greater net primary productivity for savanna systems. However, moderation also means 
acknowledging that there are limits to the magnitude and extent of grazing pressures that savanna systems can tolerate. A tolerance - in Reid's words - between pastoralists and ecosystem health (including wildlife) has always existed in African savannas. When there is recognizable degradation in ecosystem health, wildlife dynamics, or livelihood security, this is a sign that the tolerance is in decline and needs to be strengthened. Reid suggests strengthening savanna tolerance by building the capacity of local and international pastoral institutions. This includes relying more on the voices and knowledges of pastoralist leaders, lawyers, and activists and viewing pastoralists as dynamic, highly educated (formally and informally), and innovative women and men that strive for opportunities within and beyond the savanna ecosystem.

If social science has contributed anything to studies of nature-society, it is that the shifting biophysical dynamics of the savanna ecosystem are intricately linked to multi-scalar social and political systems - systems that are also in constant flux. For Reid, an ecologist by training, presenting the middle ground means engaging with the complex nature of such systems that are often excluded from ecological studies. With this in mind, Reid has beautifully enfolded the political and the social dimensions into the ecological - a task that is tremendously daunting for many scientists and researchers. Even from the perspective of social scientists, Reid gives equity to the ecological and the socio-political, in a balance that many political ecologists struggle to maintain.

One area where Reid's analysis could have taken a step further is wrangling with the global political economic processes that influence savanna systems. The most obvious route to connect savannas to global processes is through conservation. Conservation is certainly front and centre to Reid's analysis. However, one may find that while she does provide a detailed analysis of how the Western gaze has shaped African savannas as pristine nature in need of saving, she does not emphasize how contemporary institutions continue to perpetuate such visions. These institutions include not only international conservation organizations but also media outlets, tourist pressures through social media movements, and growing concerns over international security (i.e. 'Africa's War on Poaching'). The ever-growing connections between the African savanna and global political economy may unravel endless connections extending beyond Reid's original focus for this book. Yet, more direct connections to contemporary networks that shape discourses of ecology, conservation, and human-wildlife interaction may place her work in better conversation with domestic and foreign policies.

Reid's inclusive analysis is one of the most comprehensive and well-balanced examinations of human-environment interactions in African savanna ecosystems. The book is long and dense, making it sometimes hard to get through. However, Reid's willingness to engage with different epistemologies, lifelong dedication to the study of savanna ecology, and her commitment to a socially and ecologically balanced and just perspective on human-environment relations results in a job well done. Savannas of Our Birth: People, Wildlife, and Change in East Africa is an exceptional project that warrants multiple readings by students and researchers alike. The scattered empirical findings and in-depth descriptions of indigenous land-use management position the project to be a necessary text for conservation biology, anthropology, and geography curriculums. Robin Reid is to be thanked for securing the space for pastoralists within ecology and strengthening the ground for understanding human-environment systems that constitute the African savanna.

\section{Competing interests}

The authors declare that there is no competing interests.

\section{Author details}

'Department of Geography, University of Colorado, Boulder, CO, USA. ${ }^{2}$ Institute for Behavioral Studies, University of Colorado, Boulder, CO, USA.

Received: 12 August 2014 Accepted: 16 August 2014

Published online: 11 September 2014

\section{References}

Galaty, John G, and Douglas L Johnson. 1990. The world of pastoralism: Herding systems in comparative perspective. New York: The Guilford Press.

Turner, Matthew D. 2004. The political ecology and the moral dimensions of "resource conflicts": The case of farmer-herder conflicts in the Sahel. Political Geography 23:863-889.

doi:10.1186/s13570-014-0014-5

Cite this article as: Lovell and Goldman: Book review: Savannas of Our Birth: People, Wildlife, and Change in East Africa. Pastoralism: Research, Policy and Practice 2014 4:14.

\section{Submit your manuscript to a SpringerOpen ${ }^{\circ}$ journal and benefit from:}

- Convenient online submission

- Rigorous peer review

- Immediate publication on acceptance

- Open access: articles freely available online

- High visibility within the field

- Retaining the copyright to your article

Submit your next manuscript at springeropen.com 